\title{
INTRA ARTICULAR INJECTION OF HYALURONIC ACID ALONE IN COMPARISON WITH HYALURONIC ACID AND PRP IN THE TREATMENT OF INTERNAL DERANGEMENT OF TEMPOROMANDIBULAR JOINT
}

\author{
Khaled A. Saad
}

\begin{abstract}
Objectives: This study aimed to compare the efficacy of intrarticular injection of HA alone versus HA and PRP in the treatment of internal derangement of the temporomandibular joint.

Patients and Methods: Twenty patients were involved in our study, divided into two equal groups, group (1), treated with intraarticular injection of HA alone and group (2) treated with intraarticular injection of HA and PRP. All patients were diagnosed with internal derangement of the TMJ. The patients were evaluated clinically and radiographically preoperatively and postoperatively: clinically for evaluation of pain intensity, maximal mouth opening and lateral movements. Radiographically by panoramic and MRI images for detection of the condyle disc relationship and detection of any pathological changes. Postoperatively the patient's clinical data including pain intensity, maximal mouth opening and the lateral movements were evaluated at one week and 2, 3 weeks and one month and 2,3 and 6 months. Radigraphically using MRI images to determine any changes in the TMJ after injection at 6 months.
\end{abstract}

Results: Twenty patients, nineteen females and one male, their ages ranged from18-55 years with a mean of 29.5 years. The results of the clinical data including pain intensity, maximal mouth opening and lateral movements presented with significant improvements of all outcomes from preoperative to 6 months postoperatively for group (2) when compared with group (1). Radigraphically MRI after 6 months presented with no changes in the disc condyle relationship.

Conclusion: Intraarticular injection of HA and PRP considered to be strongly effective and optional treatment of internal derangement of TMJ when compared to HA alone by controlling pain, improving mouth opening and the lateral movements for up to 6 months.

\section{INTRODUCTION}

Temporomandibular joint (TMJ) disorders are a therapeutic challenge to the oral and maxillofacial surgeons, these disorders may cause pain, sounds such as clicking or crepitus and deviating jaw function, may involve internal derangement, these

* Ass. Professor, Oral \& Maxillofacial Surgery Dept., Faculty of Dentistry, Tanta University. 
disorders affect the muscles or ligaments around the joint, or a combination of these..$^{(1,2)}$

Internal derangement progresses from a stage of clicking with normal maximal mouth opening (MMO) to clicking with varying degrees of restriction in mouth opening to a stage of closed lock, causing inflammatory changes in the joint and mechanical dysfunction. The pathogenesis of internal derangement of the termporomandibular joint was developed from a disc displacement theory to more emphasis on the biochemical theory, by focusing on the biochemistry of the synovial fluid of temporomandibular joint diseases. The role of inflammation has been investigated and proposed as an underlying mechanism of pain and dysfunction of temporomandibular joint. ${ }^{(3-6)}$

Treatment of termporomandibular joint dysfunction did not respond to conservative treatment was surgical disc repair and repositioning to reestablish normal maximal mouth opening. Recently arthroscopy, simple lysis and lavage with minimally invasive procedures found to be highly effective in reestablishing normal MMO and relieving the symptoms, despite the disc position not having been corrected. ${ }^{(7-9)}$

Visco supplementation with intra articular HA injection in knee joint osteoarthritis is widely regarded as an effective treatment in improving pain and function due to its effect on articular cartilage acting as lubricant and shock absorbent. ${ }^{(10-13)}$

Hyaluronic acid is a component of synovial fluid used in the treatment of termporomandibular joint disorders, presents a therapeutic agent either as an adjunct medication after arthrocentesis or used as a therapeutic intra-articular injection. The use of hyaluronate for lubrication of synovial tissue has been established because of its composition similar to the synovial fluid of the TMJ as it consists of hyaluronic acid-protein complex with glycosaminoglycans. ${ }^{(13)}$
Hyaluronate is a good soft tissue lubricant under low loads and may exert important interactions with the synovial lining to preserve the physical properties, especially its characteristic smoothness and low friction surfaces. Hyaluronate when used as an intra-articular injection and been reported to prevent intra-articular adhesions and elicit little immune response when injected into humans or animals. ${ }^{(12)}$

Hyaluronic acid is a naturally occurring as a polysaccharide in the synovial fluid and is responsible for the eleastoviscosity of synovial fluid. It is a large glycosaminoglycan which is composed of long repeating disaccharides of glucuronic acid and $\mathrm{N}$-acetyleglucosamine. ${ }^{(13)}$

The use of platelet-rich plasma (PRP) help to accelerate healing of musculoskeletal soft tissue injuries, bone grafts, osteoarthritis (OA), and even skin ulcers. Although the long-term effects of PRP remain controversial, the high concentration of autologous growth factors in PRP is expected to reduce the time needed for healing. ${ }^{(14-18)}$

The clinical outcomes achieved with HA and PRP for OA have been published. However, the clinical results of simultaneous HA and PRP injections have not yet been reported. Recently, Sato et al., $2001^{(16)}$ published an in vitro study of the synergistic anabolic actions of HA and PRP on cartilage regeneration in $\mathrm{OA}$.

The objectives of this study is to compare the efficacy of intra articular injection of HA alone versus $\mathrm{HA}$ and PRP in the treatment of internal derangement of the TMJ.

\section{PATIENTS AND METHODS}

Twenty patients were involved in our study suffering from internal derangement of the temporomandibular joint and selected from the outpatient clinic of Oral and Maxillofacial Surgery Department, Faculty of Dentistry, Tanta University. 
Patients involved in this study were complaining of: pain over the region of temporomandibular joint, joint noises (grating, clicking and popping) produced during mastication, and the patients not respond to the conservative treatment (NSAIDS, soft diet, hard occlusal splint, hot fomentation on the affected temporomandibular joint and muscles).

The patients excluded from the study: patients with ankylosis of the temporomandibular joint, neurological disorders as epilepsy, local skin infection at the region of the joint, and patients with medical contraindications as end stage renal and hepatic failure and uncontrolled diabetic patients, blood diseases, connective tissue diseases as systemic lupus erythromatosis and rheumtoid arthritis.

\section{The patients were divided into two groups:}

- Group (1): Including (10) patients treated with arthrocentesis followed by hyaluronic acid injection alone.

- Group (2): Including (10) patients treated with arthrocentesis followed by intra-articular injection of hyaluronic acid and PRP.

All patients were evaluated clinically and radiographically preoperatively.

\section{A- Clinically:}

\section{Joint examination:-}

- By palpation: to detect of the tenderness during the maximal mouth opening, clicking and crepitus over the joint region.

- By auscultation: by using stethoscope, grating and clicking sounds are heard during jaw movements.

\section{Oral examination:}

To detect loss of teeth, premature contact of teeth, cuspal interference during excursions of the jaw, mal-positioned and abnormally erupted teeth, improperly conserved teeth with resultant occlusal and periodontal problems, all contribute to occlusal disharmony.

Detection of degree of mouth opening was measured as the distance between the incisal edge of the upper and lower central incisors and the range of lateral excursion of the mandible by measuring the distance between the upper and lower incisors midlines on jaw movement to the right and left sides respectively by ruler graded in millimeters at maximum pain free mouth opening.

Facets and grinding of occlusal surface of anterior and posterior teeth are indicators for the nervous tension of patients (bruxism and clenching) play an important role in TMJ internal derangement.

Detection the degree of pain and location by using visual analog scale (VAS) by drawing a circle on the diagram to indicate the site of pain, and pain score from (0 to 10) (0 is pain free and 10 is severe pain).(Diagram 1)

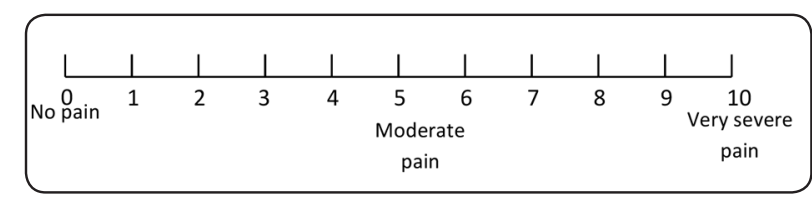

Diagram (1): Numerical visual analog scale circles the number that represents the severity of pain intensity.

\section{B-Radiographical examination by:}

- Panoramic radiograph was taken to detect local causes of internal derangement of the temporomandibular joint and additional help to determine the pathology of the joint.

- Magnetic Resonance Images MRI: applied to image the bony and soft tissues of the TMJ. Sagittal and coronal planes in opened and closed positions to help in diagnosis of the pathology of the disc as perforations, adhesions or fragmentation 


\section{Technique of injection:}

Arthrocentesis is performed by introducing two needles into the upper joint space. This permits massive lavage of the joint.

The patient is seated at a 45 angle, with the head is turned to the unaffected side to provide an easy approach to the affected joint. Proper preparation of the injection site (disinfection the site by using povidine iodine), local anesthesia containing vasoconistrictor (mepivacaine $\mathrm{Hcl}$ with levonordefrin 1:20000) is injected into the preauricular subcutaneous tissue to decrease potential bleeding from the subcutaneous blood vessels. The external auditory meatus is blocked with cotton soaked in mineral oil . The point of needle insertion is marked on the skin. A line is drawn from the middle of the tragus to the outer canthus. The posterior point of entry is located along the canthotragal line, $10 \mathrm{~mm}$ from the middle of the tragus and, $2 \mathrm{~mm}$ below the line. The anterior point of entry is placed, $10 \mathrm{~mm}$ farther along the line and, $10 \mathrm{~mm}$ below it as in fig.(1). These marking over the skin indicate the location of the articular fossa and eminence of the temporomandibular joint.

A local anesthesia is injected at the planned entrance points, avoid penetration of the joint space.

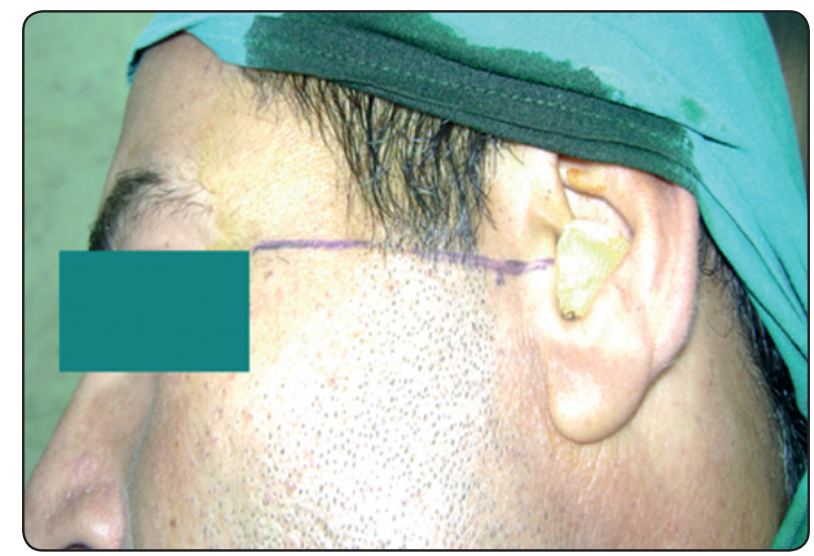

Fig (1): Cantho-tragal line with posterior point $10 \mathrm{~mm}$ from the middle of the tragus and $2 \mathrm{~mm}$ below the line and the anterior point $20 \mathrm{~mm}$ from the middle of the tragus and $10 \mathrm{~mm}$ below the line.
A 19 gauge needle connected to a syringe filled with lactated ringer's, then inserted into the superior compartment at the articular fossa with the direction of forward upward and inward with 45 degree to skin surface (posterior point). The solution is injected and immediately aspirated .The fluid in the syringe is often sucked in the joint space, which is normally has negative pressure.

A second 19-gauge needle (anterior needle) is then inserted into the distended joint in the area of articular eminence with direction backward upward and inward angulated 45 degree to the skin surface to enable free flow of ringer's solution through the superior compartment as in fig. (2). Injection of $(1 \mathrm{ml})$ of hyaluronic acid into the superior joint space after arthrocentesis, in patients of group (1). fig. (3)

\section{Preparation of PRP:}

$20 \mathrm{ml}$ of peripheral blood for PRP preparation were collected from the median cubital veins of each donor using $\alpha 21$-gauge needle, no anticoagulant or activation materials, such as Calcium chloride, using a commercial PRP separation system.

From each donor, $1.0 \mathrm{ml}$ of PRP were prepared mixed with $0.1 \mathrm{ml} \mathrm{HA}$ and injected into the superior joint space this for group (2). (Fig.4) ${ }^{(19)}$

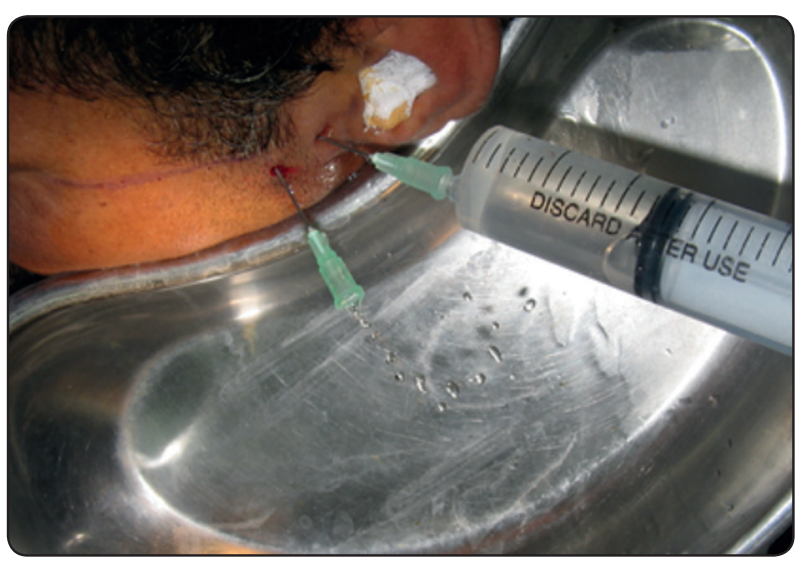

Fig (2): Insertion of the first needle in posterior point and the second needle in an anterior point into the joint space. 


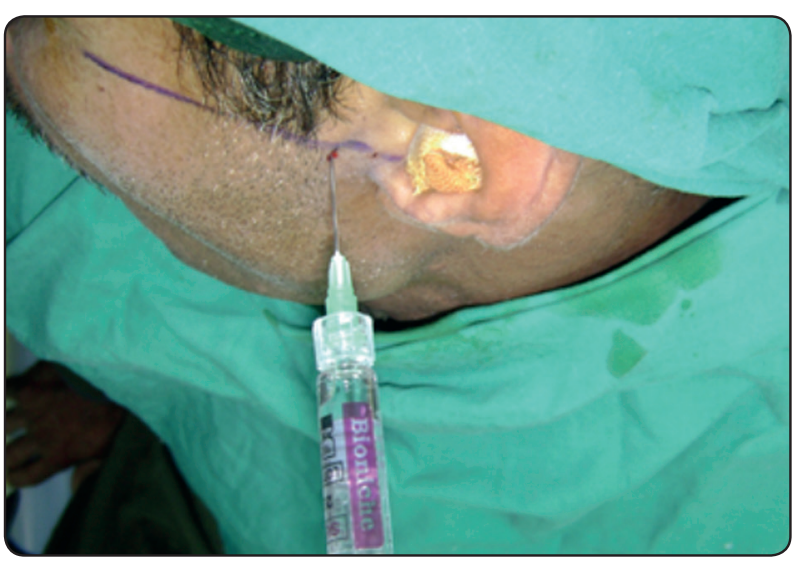

Fig (3): Injection of one $\mathrm{ml}$ hyaluronic acid through posterior needle group (1)

\section{Post-operative evaluation:}

Patients were evaluated clinically to check pain intensity and location by using visual analog scale (VAS), clicking degree with maximal mouth opening, and lateral excursion of mandible at one week, two and three weeks, one month, three and six months after injection postoperatively for both groups and radiographically for both groups using MRI to determine any differences in the disc condyle relationship postoperatively at six months.

\section{RESULTS}

Twenty patients were involved in this study, comprised nineteen females and one male, their ages ranged from 18 to 55 years with a mean of 29.5years.The diagnosis of internal derangement was based on clinical and radiographic findings and the patients were divided into two groups:-

\section{$\operatorname{Group}(1):$}

Including (10) patients: one male and nine females, two with bilateral and eight with unilateral TMJ internal derangement. Their ages ranged from 18-45 years (with a mean of 25.7) in which arthrocentesis performed followed by hyaluronic acid injection alone.

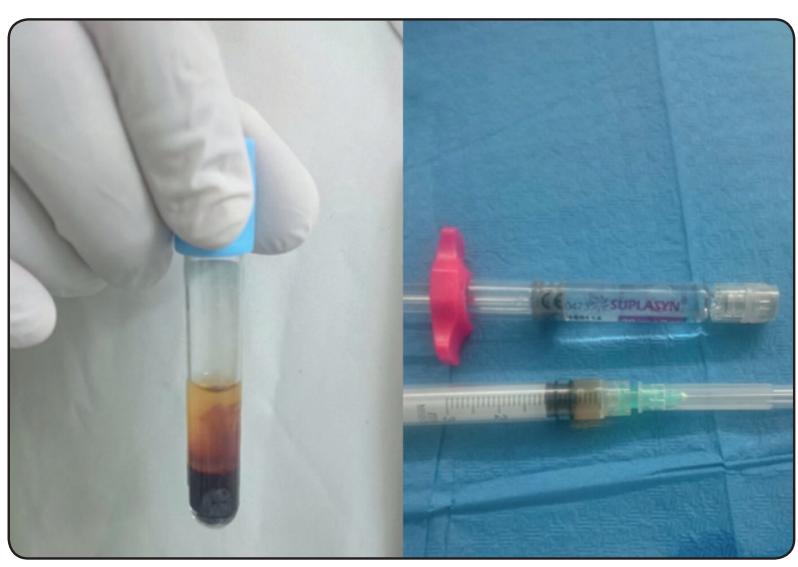

Fig (4): PRP after preparation and for injection in the syringe (one $\mathrm{ml}$ )

\section{Group (2):}

Including (10) patients: all of them were females, eight patients with unilateral and two with bilateral TMJ internal derangement. Their ages ranged from 18 to 55 years (with a mean of 26.5) in which arthrocentesis was performed followed by hyalorunic acid injection and PRP.

\section{Evaluation of the clinical data:}

\section{Pain intensity:}

According to numerical visual analogue scale (VAS):- as in table (1). Mean pain score for group (1) was $6.9 \pm 1.20$ and for group (2) was $6.7 \pm 1.337$ preoperatively. Mean pain score for group (1) was $0.690 \pm 0.509$ and for group (2) was $0.670 \pm 0.527$ postoperatively at 6 months. The decrease in pain intensity from preoperative to 6 months postoperative was found to be statistically significant in group (2) as in group (1). There are improvement outcomes of pain during 6 months evaluation of group (2) when compared with group (1).

\section{Maximal mouth opening:}

Mean MMO for (group 1) was $25.7 \pm 3.5 \mathrm{~mm}$ and for (group 2) was $28.4 \pm 2.066 \mathrm{~mm}$ preoperatively and the mean MMO for group (1) was 42.4 $\pm 3.44 \mathrm{~mm}$ 
and for group (2) was $40.7 \pm 1.424 \mathrm{~mm}$. The increase in maximal mouth opening from preoperative period to 6 months postoperatively was found to be statistically significant in group (2) as in group (1). So, there is improvement outcome of MMO during 6 months evaluation of both groups.

\section{Lateral movement:}

Mean lateral movement for group (1) $5.22 \pm 1.2 \mathrm{~mm}$ and for group (2) $5.71 \pm 1.11 \mathrm{~mm}$ preoperatively. Mean lateral movement for group (1) $9.46 \pm 0.98 \mathrm{~mm}$ and for group (2) $9.71 \pm 1.96 \mathrm{~mm}$ postoperatively at six months, this significantly determined improved the lateral movements of $(\mathrm{G} 2)$ when compared with (G1)

TABLE (1): Statistical comparison of pain intensity (VAS)of the two groups:

\begin{tabular}{|c|c|c|c|c|c|c|c|c|}
\hline & \multicolumn{6}{|c|}{ Pain intensity } & \multirow{2}{*}{\multicolumn{2}{|c|}{ Mann-Whitney Test }} \\
\hline & \multicolumn{3}{|c|}{ Group I } & \multicolumn{3}{|c|}{ Group II } & & \\
\hline & Mean & \pm & SD & Mean & \pm & SD & $\mathbf{Z}$ & P-value \\
\hline Pre-operative & 6.90 & \pm & 1.20 & 6.700 & \pm & 1.337 & -0.388 & 0.698 \\
\hline After 1 week & 4.40 & \pm & 0.97 & 3.500 & \pm & 0.707 & -3.385 & $<0.001 *$ \\
\hline After 2 weeks & 1.20 & \pm & 0.79 & 1.600 & \pm & 0.699 & -3.782 & $<0.001 *$ \\
\hline After 3 weeks & 0.509 & \pm & 0.71 & 0.950 & \pm & 0.438 & -3.693 & $<0.001 *$ \\
\hline After 1 month & 0.750 & \pm & 0.69 & 0.850 & \pm & 0.474 & -3.900 & $<0.001 *$ \\
\hline After 3months & 0.600 & \pm & 0.429 & 0.500 & \pm & 0.527 & -3.751 & $<0.001 *$ \\
\hline After 6 months & 0.690 & \pm & 0.509 & 0.670 & \pm & 0.527 & -3.853 & $<0.001 *$ \\
\hline
\end{tabular}

$P<0.05$ (significant)

TABLE (2): Statistical comparison of the maximal opening between the two groups:

\begin{tabular}{|c|c|c|c|c|c|c|c|c|}
\hline & \multicolumn{6}{|c|}{ Maximal mouth opening by millimeters $(\mathrm{mm})$} & \multirow{2}{*}{\multicolumn{2}{|c|}{ Mann-Whitney Test }} \\
\hline & \multicolumn{3}{|c|}{ Group I } & \multicolumn{3}{|c|}{ Group II } & & \\
\hline & Mean & \pm & SD & Mean & \pm & SD & $\mathbf{Z}$ & P-value \\
\hline Pre-operative & 25.7 & \pm & 3.5 & 28.4 & \pm & 2.066 & -2.102 & 0.05 \\
\hline After 1 week & 31.3 & \pm & 2.75 & 35.9 & \pm & 2.424 & -6.555 & $<0.001 *$ \\
\hline After 2 weeks & 33.1 & \pm & 2.28 & 36.5 & \pm & 1.65 & -8.308 & $<0.001 *$ \\
\hline After 3 weeks & 34.9 & \pm & 1.52 & 38.9 & \pm & 1.524 & -11.739 & $<0.001 *$ \\
\hline After 1 month & 36.95 & \pm & 1.42 & 39.9 & \pm & 1.524 & -18.124 & $<0.001 *$ \\
\hline After 3months & 39.3 & \pm & 3.542 & 40.6 & \pm & 1.524 & 14.895 & $<0.001^{*}$ \\
\hline After 6 months & 42.4 & \pm & 3.44 & 40.7 & \pm & 1.524 & 11.869 & $<0.001 *$ \\
\hline
\end{tabular}

$P<0.05$ (significant) 


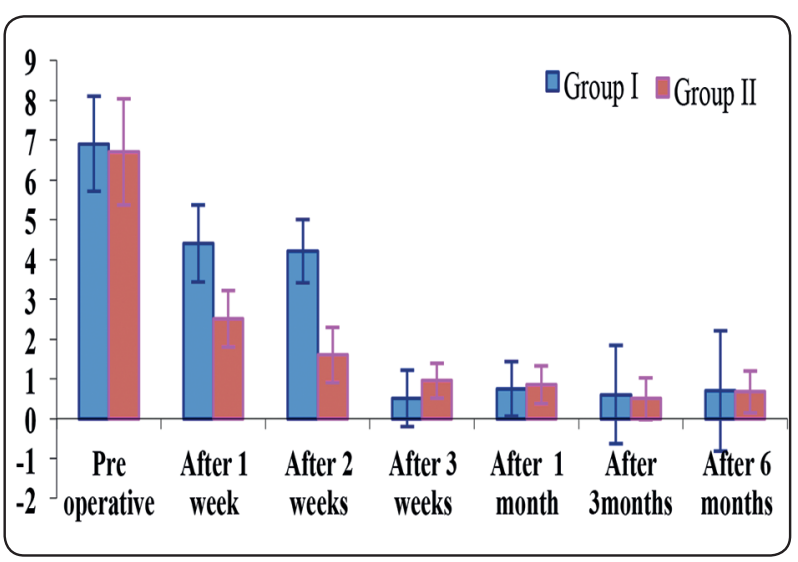

Fig (5): Showing significant decrease of pain intensity of both groups.

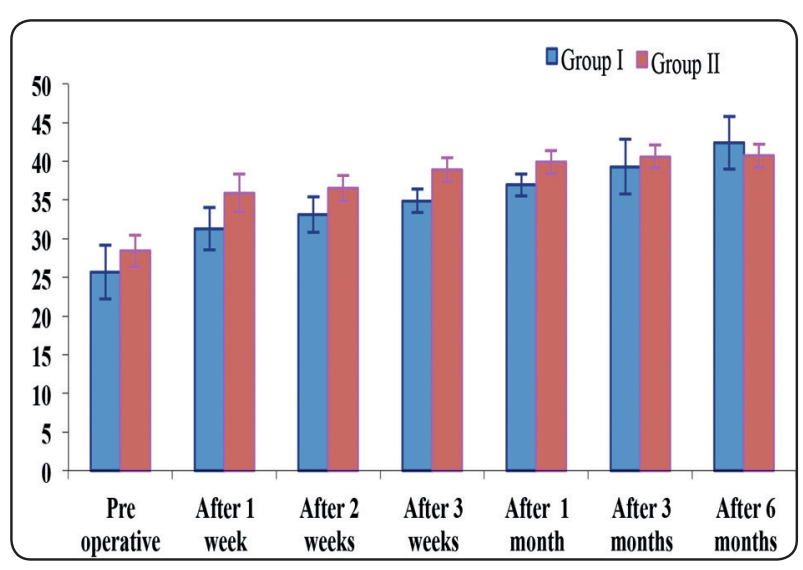

Fig (6): Showing significant increase in maximal mouth opening (MMO) in both groups.

TABLE (3) Statistical comparison of the lateral movements for both groups

\begin{tabular}{|c|c|c|c|c|c|c|c|c|}
\hline & \multicolumn{6}{|c|}{ Lateral movement by millimeters (mm) } & \multirow{2}{*}{\multicolumn{2}{|c|}{ T-test }} \\
\hline & \multicolumn{3}{|c|}{ Group I } & \multicolumn{3}{|c|}{ Group II } & & \\
\hline & Mean & \pm & SD & Mean & \pm & SD & $\mathbf{T}$ & P-value \\
\hline Pre-operative & 5.22 & \pm & 1.2 & 5.71 & \pm & 1.11 & 0.948 & 0.355 \\
\hline After 1 week & 7.12 & \pm & 2.31 & 7.71 & \pm & 1.72 & 0.648 & 0.525 \\
\hline After 2 weeks & 8.23 & \pm & 1.78 & 9.1 & \pm & 1.92 & 1.051 & 0.307 \\
\hline After 3 weeks & 8.82 & \pm & 1.88 & 9.76 & \pm & 1.98 & 1.089 & 0.290 \\
\hline After 1 month & 8.00 & \pm & 1.01 & 9.8 & \pm & 1.76 & 3.740 & $<0.001 *$ \\
\hline After 3months & 9.15 & \pm & 1.89 & 9.77 & \pm & 1.97 & 4.216 & $<0.001 *$ \\
\hline After 6 months & 9.46 & \pm & 0.98 & 9.71 & \pm & 1.96 & 6.133 & $<0.001^{*}$ \\
\hline
\end{tabular}

$P<0.05$ (significant)

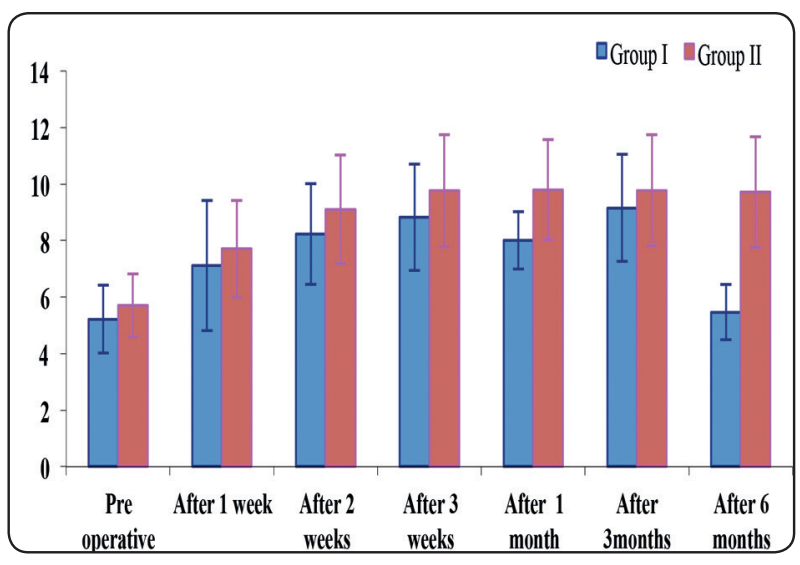

Fig (7): Showing significant increase of the lateral movement for both groups.

\section{Radiographic findings according to MRI images}

\section{R I finding pre-operatively}

All patients showed normal MRI features of both mandibular condyles and temporal articular eminences with no evident focal bony lesion detected. MRI images were used for analysis of the disc condyle relationship that shows the disc, condyle, articular eminence and glenoid fossa and group I including five patients showed unilateral anterior disc displacement with reduction of the left TMJ disc and three patients of right side of the 
TMJ. Two patients showed bilateral anterior disc displacement of both right and left TMJ discs with reduction. Group 2, six patients showed unilateral anterior disc displacement with reduction of left TMJ and two patients of right side of the TMJ. Two patients showed bilateral anterior disc displacement with reduction of TMJ.

\section{R I finding postopertively}

There was no difference in disc condyle relationship pre and post-operative in both groups Fig (8-10).

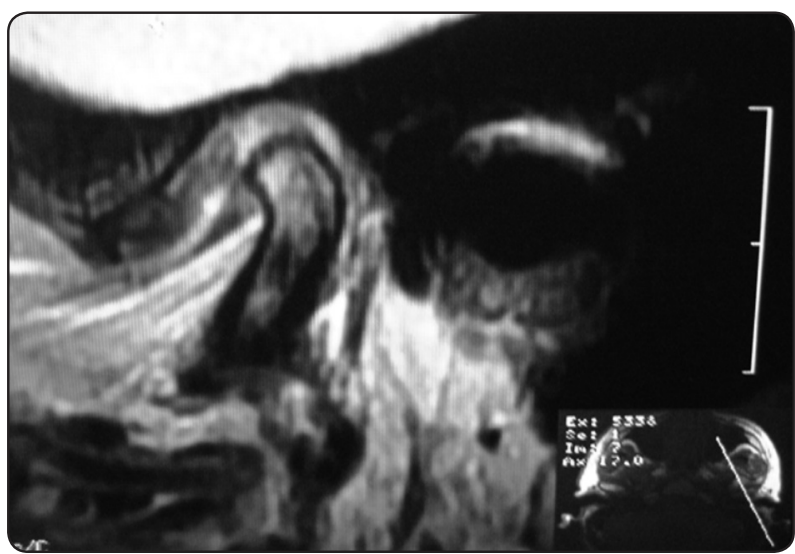

Fig (8): Right side anterior disc displacement with reduction.

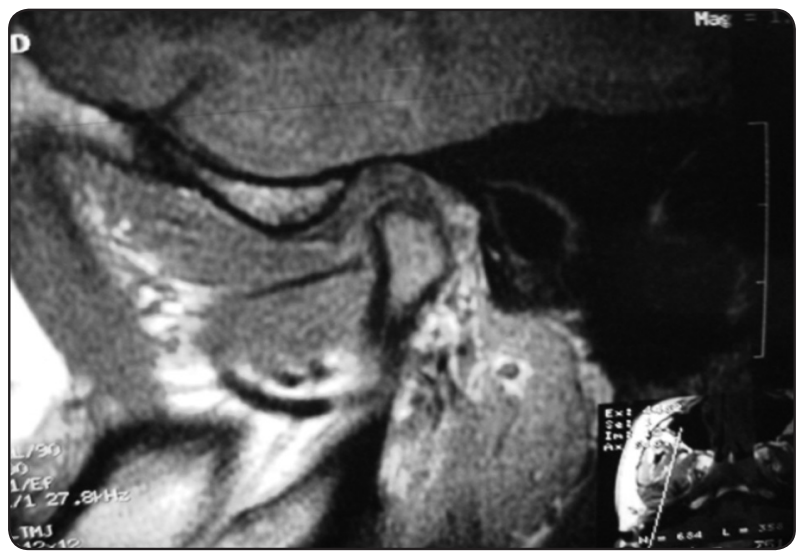

Fig (9): Left side anterior disc displacement with reduction.

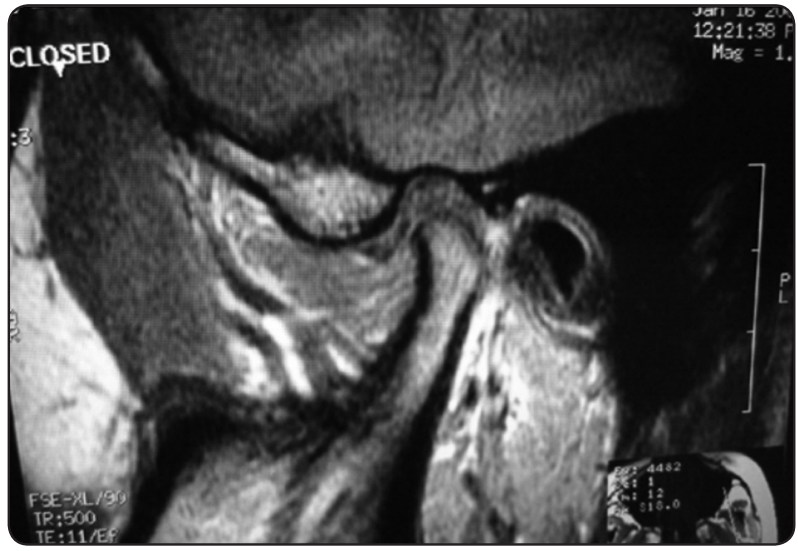

Fig (10): Six months post-operative MRI shows no change of the disc position.

\section{DISCUSSION}

Temporomandibular joint (TMJ) disorders are therapeutic challenge to the oral and maxillofacial surgeons. These disorders may cause pain, sounds such as clicking or crepitus, and irregular or deviating jaw function, internal derangement of the articular disc of the TMJ was described as a potential clinical problem more than 100 years ago .It causes joint pain, limited mandibular movement, joint sounds, and osteoarthrotic changes in the TMJ. ${ }^{(1,8)}$

Therefore, we aimed to compare the use of one of the most contemporary methods for the treatment of TMJ disorders and internal derangement which was arthrocentesis with intra articular injection of hyaluronic acid as in group (1) were presented with ten patients, and in group (2), arthrocentesis with intraarticular injection of hyaluronic acid and platelet rich plasma (PRP), also comprised ten patients.

Conservative measures should be tried before any interventional procedures are to be considered according to (Dolwick, 1983 and Nishimura, et al., 2004). ${ }^{(8,14)}$ These non-invasive measures include all or some: a soft diet, jaw exercises (either patient directed, or a course of active physiotherapy), nonsteroidal analgesic agents, and bite raising appliances and the hard splint is better than the soft splint. 
Arthrocentesis is recognized as a first line of surgical intervention in patients who do not respond to conservative measures and is thought to break down adhesions within the joint and decrease inflammatory mediators including cytokines and interleukins, which result in improvement in both mouth opening and function. ${ }^{(19-22)}$

An efficient lubrication system in the TMJ is absolutely necessary helping the disc to slide along the slope of the eminence, hyaluronic acid is responsible for free joint movement and highly effective lubricants. Hyaluronic acid, (a high molecular weight mucopolysaccharide), forms a full fluid film with long term lubricating effect, so moving the inflammatory mediators that are responsible of pain and keeps the articular surfaces separated and prevents friction. ${ }^{(23-28)}$

In a study achieved by ((Kop, et al., 1991 ${ }^{(20)}$ and Alpaslan and Alpaslan, 2001) $)^{(21)}$ on arthrocentesis followed by intra articular injection of hyaluronic acid gave better results than arthrocentesis only and this was in agreement of results of our study where there are significant improvement outcomes of pain intensity, maximal mouth opening and lateral movements of the jaw as in patients of both groups.

In our study pain intensity decreased significantly in patients of both groups. In group (1) the patients treated with injection of hyaluronic acid after arthrocentesis (mean of pain intensity pre injection was 6.9and six months after injection became 0.69 with improvement 90\%) and these results were similar to those obtained by (Kaneyamu et al., 2004). (19) The patients of group (2) treated with injection of hyaluronic acid and PRP,(mean pain intensity preinjection was 6.7 and six months after injection become 0.67 with improvement $95 \%$ ) there was greater decrease in pain intensity as PRP can stimulate the healing process at different tissues by releasing various growth factors and cytokines that are released by platelets and adding of HA to PRP allow to increase the concentration of growth factors released around the HA stimulating the healing process decreasing pain intensity according to (Lio et al., 2016), ${ }^{(29)}$ as they reported that the use of a mixture of PRP and HA help to relief pain by increasing released growth factors for stimulating the healing process.

Maximal mouth opening before injection for group (1) with a mean of $25.7 \mathrm{~mm}$ and after six months after injection with HA the MMO significantly increased with a mean of 42.2 , and in group (2) in which maximal mouth opening before injection with a mean of $28.4 \mathrm{~mm}$ and after injection with HA mixed with PRP the maximal mouth opening significantly increased with a mean of $40.7 \mathrm{~mm}$ these results were similar to those obtained by (Nitzan and Dolwic, 1990),,$^{7}$ (Zhong and Zhou, 2004), 22 ( Lio et al., 2016) $)^{29}$, that during the treatment of internal derangement and osteoarthritis, correcting the pain, improving mouth opening and mandibular function.

The lateral movement of the mandible improved in both groups after one month and continued to be increased in both groups where the lateral movement pre injection for group (1) was (mean 5.22mm), and after injection became (mean $9.46 \mathrm{~mm}$ ) at six months, for group (2), the lateral movement preinjection was (mean $5.71 \mathrm{~mm}$ ) and after injection became (mean $9.71 \mathrm{~mm}$ ) at six months. These results similar to that obtained by (Ishimaru et al., 2003) ${ }^{25}$ (Serban et al., $2008)^{26}$ reported improvement of lateral movements of the mandible after injection of hyaluronic acid in patients with internal derangement of TMJ and this was in agreement with other results of our study.

In our study after follow up periods two patients of group (1) still suffering from TMJ clicking (20\% of patients) and one patient of group (2) still suffering from TMJ clicking (10\% of patients), and these results in agreement with (Guarda - Nardini et al., 2007 $)^{23}\left(\right.$ Lio et al.,2016) ${ }^{29}$

In our study the selection for HA because of it closely resembles the molecular weight of endo genous HA in the extra-cellular matrix. Also, the studies have achieved by (Grace et al., 2003) $)^{(2)}$, (Yoga et al., 2009) (27), determined that 
HA regulates the gene expression of osteoarthritis associated cytokines and enzymes in fibroblast like synoviocytes, also HA has antinflammatory property and regulates the support cells for cell proliferation, also HA resides longer in the synovial joint, this property help to inhibit glycosamino glycan release from the articular cartilage and results in better outcome in the long run this gives significant improvement during six months evaluation compared to the pre injection in both groups and this in agreement of studies achieved by (Saturveithan et al.,2016). ${ }^{(32)}$

According to studies achieved by (Guidolin et al., 2004) $)^{(28)}$, (Wang et al., 2006) ${ }^{(30)}$, (Anitua et al., 2012) $)^{(33)}$ and (Berenbaum et al., 2012) ${ }^{(34)}$, where they explained that combination of HA and PRP promoting cartilage repair as PRP is a biological therapy delivering concentrated platelets to accelerate healing and regeneration of articular cartilage, PRP rich in growth factors which induce the differentiation of mesenchymal stem cells into chondrocytes so, increase cell proliferation, also, suppresses inflammatory mediators and induces matrix deposition and slow down degeneration, all these properties helping to decrease and improve pain, decrease clicking and improve the lateral movements as appeared clinically from our study of group 2 in addition to these properties, autologous venous blood versus synthetic chemicals, it eliminates the risk of allergic reactions and possible transmission of infection.

Although clinical improvement of patients of group (2) and group (1), radigraphically there were no difference in disc condyle relationship (no positional change in disc) pre- and post- operative in both groups, and these results similar to that obtained by (Sato et al., 2001) ${ }^{16}$,(Guarda-Nardini et al., 2002)18, (Alpaslan and Alpaslan 2001) ${ }^{21}$ and (Ishimaru et al., 2003 ${ }^{25}$ ) showed that the use of hyaluronic acid in non-reducing TMJ disc displacement obtaining overall improvement in clinical signs and symptoms, however the disc displacement remained uncorrected.
Finally, the psychological management of the patients with temporomandibular joint disorders must be the first line of treatment where the psychosocial condition and good support is an integral part in treatment.

\section{CONCLUSION}

Intraarticular injection of HA and PRP considered to be strongly effective and optional treatment of internal derangement of TMJ when compared to HA alone by controlling pain, improving mouth opening and the lateral movements for up to 6 months.

\section{REFERENCES}

1. Quinn JH, Bazan NJ: Identification of prostaglandin E2 and Leukotriene B4 in the synovial fluid of painful and dysfunctional temporomandibular joints. J Oral Maxillofac Surg. 48: 968; 1990.

2. Grace $\mathbf{H}$, Michael $\mathbf{H}$, Timothy $\mathbf{M}$ et al.: Intra articular hyaluronic acid in treatment of knee osteoarthritis: a metaanalysis. JAMA 290:3115-3121;2003.

3. Detamore MS, Athanasiou KA, Mao J.: TMJ arthroscopy. A diagnostic and surgical atlas, first edition. J.B. Lippincott Company, Philadelphia: 2-7; 2007.

4. Tanaka E, Detamore MS, Mercuri LG: Use of hylan G-F 20 for visco supplementation of the temporomandibular joint for the management of osteoarthritis: a case report. $\mathrm{J}$ Orofac pain:9 (4):375-9; 2008.

5. Sato J, Segami N, Nishimura M, et al.: Expression of interleukin 6 in synovial tissues in patients with internal derangement of the temporomandibular joint. Br J Oral Maxillofac Surg.41(2):95-10; 2003.

6. Dolwick MF: Is there a role for temporomandibular joint surgery? Br J Oral Maxillofac surg 32: 307;1994.

7. Nitzan DW, Dolwick MF: Arthroscopic lavage and lysis of the temporomandibular joint: a change in perspective. J Oral Maxillofacial Surg.48:798-81;1990.

8. Dolwick MF, Kaytzberg RW, Helms CA: Internal derangement of the temporomandibular joint Fact of friction. J Prosth Dent.49:415-8;1983.

9. Neo H, Ishimaru, Kurita K, Goss AN: The effect of hyaluronic acid on experimental temporomandibular joint osteoarthrosis in the sheep. J Oral Maxillofac Surg.55 (10): 1114-9; 1997 
10. Chen WH, Lo We, Hsu Wc, et al.: Synergistic anabolic actions of hyaluronic acid and platelet rich plasma on cartilage regeneration in osteoarthritis therapy. J Biomaterials.35:9599-9607;2014.

11. Bjornland T, Gjaerum A A, Moystad A. J.: asteo- arthrosis osteoarthritis in temporomandibular joint and masticatory muscle disorders. Copenhagen: Munksgard. P.298-314; 2007.

12. Nitzan DW, Dolwick WF: An alternative explanation for the genesis of closed lock symptoms in the internal derangement process. J Oral Maxillofac Surg.49:810$815 ; 1991$.

13. Dimitroulis G, Dolwick MF, Martinez A.: Temporomandibular joint arthrocentesis and lavage for the treatment of closed lock: a follow-up study. Br J Oral Maxillofac Surg.33 (I): 23-6: discussion 26-7;2005.

14. Nishimura M, Segami N, Kaneyama K, et al.: Comparison of cytokine level in synovial fluid between successful and unsuccessful cases in arthrocentesis of the temporomandibular joint. J Oral Maxillofac Surg.62 (3):284-7 discussion 287-8;2004.

15. Long X, Chen G, Cheng A H, Cheng Y, Deng M: Shortterm outcome of arthoscopic surgery of the temporomandibular joint osteoarthrosis and internal derangement: A randomized controlled clinical trial. Br J Oral Maxillofac Surg.31: 3-14;2009.

16. Sato S, Oguri S, Yamaguchi K, et al.: Pumping injecting of hyaluronic acid for patients with non-reducing disc displacement of the temporomandibular joint: two years follow-up J CranioMaxillofac Surg.29: 89-93;2001.

17. Nitzan DW, Etsion I: Adhesive force, the underlying cause of the disc anchorage to the fossa and eminence in the temporomandibular joint -a new concept. Int J Oral Maxillofacial Surg.31(1):94-9;2002.

18. Guarda-Nardini L, Tito R, Staffieri A, et al.: Treatment of patients with arthrosis of the tempromoandibular joint by infiltration of hyaluronic acid: a preliminary study. Eur Arch Otorhinolaryngol,84:259-279;2002.

19. Kaneyama K, Segami N, Nishimura M, et al.: The ideal lavage volume for removing bradykinin, interleukin- 6 and protein from the temporomandibular joint by arthrocentesis. J Oral Maxillofac Surg.62: 657-61;2004.

20. Kopp S, Akennan S, Nilner M.: Short term effects of intra articular sodium hyaluronate, glucocorticoid and saline in- jection on rheumatoid arthritis of the temporomandibular joint. J CranioMandib Disord.5(4):231-8;1991.

21. Alpaslan C, Alpaslan G.H.: Efficacy of temporomandibular joint arthrocentesis with and without injection of sodium hyaluronate in treatment of internal derangement, J Oral Maxillofac Surg. 59:613-618;2001.

22. Zhong W Q and Zhou G: Intra articular injection dilatation of TMJ for the treatment of anterior disc displacement without reduction, Shanghai Kou Qiang YiXue.13 (1):2326;2004.

23. Guarda-Nardini L, Stifano M, Brombin C.: A one year case series of arthrocentesis with hyaluronic acid injections for the temporomandibular joint osteoarthritis. Oral Surg Oral Med Oral Path 103(6): 14- 22;2007.

24. Carvajal WA, Laskin DM: Long term evaluation of temporomandibular joint arthrocenresis in treatment of internal derangement. J Oral Maxillofac Surg58:852-7;2000.

25. Ishimaru J I, Ogi N, Mizui T, Miyamoto K.: Effect of arthrocentesis on disorders of temporomandibular joints. $\mathrm{Br}$ J Oral MaxillofacSurg.41(5):323-328;2003.

26. Serban MA, Yang G, Prestwich GD: Disk interference disorders. In: Zarb G, Carlsson G, Sesscle B, Mohl N, Editors. Temporomandibular joint and masticatory muscle disorders. Copenhagen: Munksguard.p271-276;2008.

27. Yoga R, Mukaram M, Ramachandram: Hyaluronate for the treatment of osteoarthritis of the knee: A retrospective review of 45 patients. Mal J orthop.3:4-7;2009.

28. Guidolin DD, Ronchetti IP, Guerra D, Friz Ziero L: Morphological analysis of articular cartilage Biopsies: Randomized, clinical study comparing of effects of 500-730 KDa sodium hayluronate (Hyalgan) and Methylprednisolone acetate on primary osteoarthritis of the knee. J of Physician. 50:249-256;2004.

29. Lio K, Furukawa KI, Tsuda E, Yamamoto Y, Maeda S, Naraaka T, Kimura Y, Ishibashi Y: Hyaluronic acid induces the reduce of growth factors from platelet rich plasma. Asia Pacific Journal of Sports and Medicine, Arthroscopy, Rehabilitation and Technology. 4:27-32;2016.

30. Wang CT, Lin YT, Hou SM: High molecular weight hyaluronic acid down regulates the gene expression of osteoarthritis associated cytokines and enzymes in fibroblast like synoviocytes from patients with early osteoarthritis, osteoanthritis cartilage. 14(12):1237-1247; 2006. 
31. Nagano O: Mechanism and biological significance of $C D$ 44cleavage. Cancer Sci 95(12):930-935;2004.

32. Saturveithan C, Premganesh G, Fakhrizzaki, Mohathir M, Karuna K, Rauf K et al.: Intraarticular hyaluronic acid (HA) and platelet rich plasma (PRP) injection versus hyaluronic acid (HA) injection alone in patient with grade III and IV knee osteoarthritis (OA): a retrospective study on functional outcome. Malaysion Orthpedic Journal. 10(2):35-40;2016.
33. Anitua E, Sanchez M, De La Fuente M, Zalduendo MM, Orive G: Plasma rich in growth factors stimulates tendon and synovial fibroblast migration and biological properties of HA. Knee Surg Sports Traumatol Arthrosca. 20:1657$1665 ; 2012$.

34. Berenbaum F, Grifka J, Cazzanigas D, Anato M, Giacavelli $\mathrm{G}$ et al:: A randomized double-blind controlled trail comparing two intra articular hyaluronic acid preparations differing by their molecular weight in symptomatic knee osteoartheitis. Ann Rheum Dis.71(9):14545-1460;2012. 